\title{
Gamma-Aminobutyric Acid System Genes-No Evidence for a Role in Alcohol Use and Abuse in a Community-Based Sample
}

\author{
Daniel E. Irons, William G. lacono, William S. Oetting, Robert M. Kirkpatrick, Scott I. Vrieze, \\ Michael B. Miller, and Matt McGue
}

\begin{abstract}
Background: While twin and adoption studies point to substantial genetic influence upon alcohol use, dependence, and other alcohol-related phenotypes, few of the genes underlying variation in these phenotypes have been identified. Markers in genes related to GABAergic activity - a system integral to many of alcohol's biological effects - have been implicated in alcohol use and alcohol-related psychopathology in linkage and association studies.

Methods: Using multiple methods, we conducted a comprehensive examination of the effects of markers in $\gamma$-aminobutyric acid (GABA) system genes in a community-based sample of 7,224 individuals assessed in early and middle adulthood. In addition to testing the effect of individual single nucleotide polymorphism (SNP) markers on alcohol-related phenotypes, we computed a polygenic score reflecting the aggregated effects of multiple GABA system SNPs. We also estimated the variance in alcohol-related phenotypes attributable to all GABA system markers considered simultaneously and conducted gene-based association tests.

Results: No method produced results indicative of an effect of GABA system variants on measures of alcohol use or misuse.

Conclusions: These results reflect alcohol-related behaviors in a population-representative sample, many of whom are still in adolescence, and in which the incidence of heavy drinking and alcohol-related symptomatology are relatively low. Contrasted with existing studies of the association between alcohol use and GABA system genes, our results suggest that the relationship may be limited to particular contexts, such as when accompanied by polysubstance abuse or a familial history of alcoholism.
\end{abstract}

Key Words: Alcohol Dependence, $\gamma$-Aminobutyric Acid, Genetics, Association, GABA.

$T$ WIN AND ADOPTION studies indicate that genetic factors are likely to substantially influence alcoholrelated behavioral phenotypes, including alcohol dependence (McGue, 1999) and quantitative measures of alcohol use (Heath and Martin, 1994). However, few individual common genetic variants have been consistently shown to have replicable effect upon alcohol use and dependence. One reason genetic association studies might fail to account for a substantial proportion of the genetic variance suggested by biometrical analyses is if the variants underlying variation in

From the Department of Psychology (DEI, WGI, RMK, MBM, MM), University of Minnesota, Minneapolis, Minnesota; Department of Experimental and Clinical Pharmacology (WSO), College of Pharmacy, University of Minnesota, Minneapolis, Minnesota; and Department of Biostatistics (SIV), University of Michigan, Ann Arbor, Michigan.

Received for publication February 14, 2013; accepted November 13, 2013.

Reprint requests: Daniel E. Irons, PhD, Department of Psychology, University of Minnesota, 75 East River Rd., Minneapolis, MN 55455; Tel.: 612-481-2133; Fax: 612-626-2079; E-mail: iron0012@umn.edu

Present address: Robert M. Kirkpatrick, Virginia Institute for Psychiatric and Behavioral Genetics, Virginia Commonwealth University, Richmond, $V A$.

Copyright (C) 2014 by the Research Society on Alcoholism.

DOI: 10.1111/acer.12352 alcohol-related phenotypes are of such small individual effect that markers tagging them do not meet thresholds for significance. Genes that belong to biological systems or pathways relevant to the effects of alcohol and have been repeatedly implicated in previous studies might be more likely to yield evidence for genetic effects reflecting the mechanisms underlying alcohol use-related behaviors.

Many of alcohol's effects-subjective, soporific, anxiolytic, and motor-skill impairing, among others-are mediated by activity involving $\gamma$-aminobutyric acid (GABA), the neurotransmitter principally responsible for inhibitory neurotransmission in the central nervous system (Kumar et al., 2009). In particular, ethanol's action is largely effected, both directly and indirectly, upon type A GABA $\left(\mathrm{GABA}_{\mathrm{A}}\right)$ receptors to mediate many of its behavioral consequences. The subunit composition of a $\mathrm{GABA}_{\mathrm{A}}$ receptor affects the nature and sensitivity of its response to ethanol exposure, and functional variation in $\mathrm{GABA}_{\mathrm{A}}$ receptor subunit genes can alter physiological and behavioral response to alcohol and other GABA-active drugs (Lobo and Harris, 2008).

GABAergic activity is also involved in mediating the effects of chronic alcohol exposure and becomes altered with the development of alcohol tolerance and dependence, and during withdrawal. Administration of GABA agonists 
increases alcohol consumption, and administration of GABA antagonists decreases alcohol consumption (Boyle et al., 1993); but while acute alcohol exposure enhances GABA activity, $\mathrm{GABA}_{\mathrm{A}}$ receptors down-regulate with chronic exposure to ethanol, resulting in diminished efficacy of alcohol (Grobin et al., 1998). Further, GABA agonists block the behavioral symptoms of alcohol withdrawal, while GABA antagonists exacerbate them (Koob, 2006). Chronic alcohol exposure also affects the expression and brain region localization of separate $\mathrm{GABA}_{\mathrm{A}}$ receptor subunits each differently, as well altering the subunit composition of the completed receptor (Enoch, 2008).

$\mathrm{GABA}_{\mathrm{A}}$ receptor subunit genes lie in clusters on chromosomes $4 \mathrm{p}(\gamma 1, \alpha 2, \alpha 4, \beta 1), 5 \mathrm{q}(\gamma 2, \alpha 1, \alpha 6, \beta 2), 15(\beta 3, \alpha 5, \gamma 3)$, and $\mathrm{X}(\varepsilon, \alpha 3, \theta)$, as well as individually on chromosomes $1 \mathrm{p}$ $(\delta), 3 \mathrm{q}(\rho 3), 5 \mathrm{q}(\pi$, outside of the cluster), and $6 \mathrm{q}(\rho 1, \rho 2)$ (Enoch, 2008). Linkage and association studies have implicated variation in several $\mathrm{GABA}_{\mathrm{A}}$ subunit genes in a variety of behavioral phenotypes related to alcohol, including dependence diagnosis (Cui et al., 2012) and symptomatology (Lind et al., 2008a), subjective intoxication and response (Lind et al., 2008b) and electroencephalographical measures (Edenberg et al., 2004) among others. Among GABA receptor subunit genes, markers and haplotypes in the $\alpha 2$ subunit gene GABRA2 have been most frequently identified with variation in alcohol response and dependence (Cui et al., 2012), and phenotypes related to other psychoactive substances (Agrawal et al., 2006), as well as externalizing conduct (Dick et al., 2006). However, there have also been studies that were unable to confirm effects of GABRA2 polymorphisms on alcohol dependence (Drgon et al., 2006; Matthews et al., 2007; Onori et al., 2010).

Type B GABA receptors $\left(\mathrm{GABA}_{\mathrm{B}}\right)$, which regulate presynaptic GABA release, among other functions (Bettler et al., 2004), are also involved in the biological effects of alcohol. $\mathrm{GABA}_{\mathrm{B}}$ agonists reduce craving for alcohol (Addolorato et al., 2002), and $\mathrm{GABA}_{\mathrm{B}}$ receptor expression is down-regulated in the hippocampus of alcoholics and alcohol-preferring rats (Enoch et al., 2012). Relative to $\mathrm{GABA}_{\mathrm{A}}$ receptor subunit genes, the effects of variation in $G_{A B A}$ receptor genes GABBR1 and GABBR2 on alcohol use in humans have been infrequently appraised, although one study observing a nonsignificant trend for association with an allele in GABBR1 allowed the possibility that variation in $\mathrm{GABA}_{\mathrm{B}}$ genes may influence alcohol dependence (Sander et al., 1999). Furthermore, a number of other genes involved in GABAergic transmission but not coding for GABA receptors have also been shown to be associated with alcohol-related outcomes. For example, single nucleotide polymorphisms (SNPs) in one of the gene isoforms for the glutamate decarboxylase enzyme (GAD1), which is involved in GABA synthesis, have been associated with initial sensitivity to alcohol and age of onset of alcohol dependence (Kuo et al., 2009).

We used multiple methods to examine the influence of markers in GABA system genes on measures of alcohol use and alcohol abuse and dependence symptomatology. In addition to $\mathrm{GABA}_{\mathrm{A}}$ receptor subunit genes, markers in a number of which have been previously associated with alcohol-related phenotypes, we also considered markers in and near genes involved in the synthesis, release, transport, and metabolism of GABA, as well as other activity related to GABA or GABA receptors. First, because individual variants conveying risk for elevated alcohol use may be of such minute effect that markers in linkage with risk alleles may fail to exceed thresholds for significance in single-SNP analyses, we calculated a polygenic score reflecting variation in alcohol use phenotypes attributable to the combined set of linkage disequilibrium (LD)-pruned GABA system SNPs, at several significance thresholds. Next, we derived an estimate of the phenotypic variance explained by the GABA SNPs in this set, from a SNP-based estimate of genetic similarity between pairs of participants who are not close genetic relatives. Finally, we examined the effect of individual GABA system genes using a gene-based test.

\section{MATERIALS AND METHODS}

\section{Sample}

Participants were drawn from 2 studies at the Minnesota Center for Twin and Family Research (MCTFR; Iacono et al., 2006): the Minnesota Twin Family Study (MTFS; Iacono et al., 1999) comprising twins and their families, and the Sibling Interaction and Behavior Study (SIBS) (McGue et al., 2007), which includes adopted and biological sibling pairs and their families. Both studies are population based and longitudinal, with an initial assessment when twins and siblings are in adolescence, and follow-up assessments every 3 or 4 years thereafter. For this study, both offspring (twins and siblings) and their parents were included in analyses. Parent data were collected at their family's first visit to the MCTFR, while for nonparental participants, data were taken from assessments conducted between ages 16.5 and 21. Only white MCTFR participants were included in the sample, as determined by clustering in principal components calculated using EIGENSTRAT (Miller et al., 2012). In all, genotypic and phenotypic data were available for 7,224 participants (Table 1), comprising 3,849 parent participants, 2,916 twins (1,901 monozygotic, 1,015 dizygotic), and 459 nonparental SIBS participants. Only participants who had ever tried alcohol in their life were included in subsequent analyses $(N=6,174,85.5 \%$ of the total sample, see Table 1).

\section{Genotyping}

GABA system SNPs used in this study were drawn from genome-wide genotyping using the Illumina 660w Quad array (Illumina, Inc., San Diego, CA), which in the MCTFR sample yielded a total of 527,829 viable SNP markers after quality-control filtering. Quality-control procedures for SNP markers and DNA samples have been previously described in detail (Miller et al., 2012). Briefly, the most common reasons for excluding markers were minor allele frequency $<1 \%$, more than 2 cross-family Mendelian inconsistencies, a call rate below $99 \%$, and a significant deviation from Hardy-Weinberg equilibrium. For SNPs that remained in the analyses after quality-control filtering, missing genotypes were replaced with the mean genotypic value for each SNP. The most common reason for excluding DNA samples from analyses was genotype call failure for more than 5,000 SNPs. 
Table 1. Descriptive Statistics for Age and Alcohol Use and Abuse Phenotypes for Parent and Adolescent Participants

\begin{tabular}{|c|c|c|c|c|}
\hline & \multicolumn{2}{|c|}{ Parents } & \multicolumn{2}{|c|}{ Adolescents } \\
\hline & Male & Female & Male & Female \\
\hline Total $N$ & 1,776 & 2,073 & 1,577 & 1,798 \\
\hline Ever tried alcohol & & & & \\
\hline$N(\%)$ & $1,753(98.7)$ & $2,036(98.2)$ & $1,150(72.9)$ & 1,235 (68.9) \\
\hline Age & & & & \\
\hline $\begin{array}{l}M(\mathrm{SD}) \\
\text { Drinking index }{ }^{\mathrm{a}, \mathrm{b}}\end{array}$ & $44.84(5.72)$ & $42.81(5.34)$ & $17.87(0.68)$ & $17.99(0.85)$ \\
\hline$M(\mathrm{SD})$ & $12.19(4.26)$ & $8.20(3.68)$ & $6.78(5.87)$ & $5.15(4.71)$ \\
\hline Past 12 months' frequency of alcohol use $e^{a, c}$ & & & & \\
\hline$M(\mathrm{SD})$ & $6.00(1.62)$ & $4.89(1.58)$ & $3.93(1.96)$ & $3.60(1.74)$ \\
\hline Past 12 months' drinks per occasion ${ }^{\mathrm{a}, \mathrm{c}}$ & & & & \\
\hline $\begin{array}{l}M(\mathrm{SD}) \\
\text { Maximum 24-hour number of drinks ever consumed }{ }^{\mathrm{a}, \mathrm{c}}\end{array}$ & $3.65(4.24)$ & $2.24(2.41)$ & $5.76(4.94)$ & $3.71(3.45)$ \\
\hline$M(\mathrm{SD})$ & $16.80(11.20)$ & $7.37(5.40)$ & $12.47(10.05)$ & $7.47(5.88)$ \\
\hline Number of times intoxicated (lifetime) ) $^{\mathrm{a}, \mathrm{c}}$ & & & & \\
\hline$M(\mathrm{SD})$ & $156.60(299.47)$ & $39.79(144.74)$ & $36.26(135.13)$ & $22.89(109.43)$ \\
\hline Alcohol abuse or dependence diagnosis (lifetime) (\%) & 50.2 & 16.1 & 22.0 & 12.7 \\
\hline No. of alcohol abuse and dependence symptoms ${ }^{a, d}$ & & & & \\
\hline$M(\mathrm{SD})$ & $1.84(2.25)$ & $0.52(1.32)$ & $0.72(1.49)$ & $0.35(1.09)$ \\
\hline
\end{tabular}

${ }^{a}$ Measures of alcohol use and symptomatology are displayed only for those who had ever tried alcohol.

${ }^{\mathrm{b}}$ The drinking index ranged for male parents 0 to 23 , for female parents 0 to 20 , for male adolescents 0 to 23 , and for female adolescents 0 to 20 .

${ }^{\mathrm{V}}$ Values for individual measures of alcohol use are displayed before recoding for inclusion in drinking index. See Supporting information for detailed item descriptions.

${ }^{\mathrm{d} D S M}$-IIIR alcohol dependence was assessed with a maximum of 9 symptoms, and DSM-IIIR alcohol abuse was assessed with a maximum of 2 symptoms, allowing for a combined maximum of 11 symptoms.

GABA system genes were selected based on their inclusion in any of 3 sources: a panel constructed to include candidate genes for addiction-related phenotypes (Hodgkinson et al., 2008), an expertcurated list of addiction-pertinent genes (Saccone et al., 2009), and a database devoted to organizing genes by biological system pathways (Kanehisa, 1996). Genes were selected if any of these sources listed them as being involved in GABA-related activity; in this way, 36 genes were selected. We examined markers within $5 \mathrm{~kb}$ upstream ( $5^{\prime}$ direction) and $1 \mathrm{~kb}$ downstream ( $3^{\prime}$ direction) of each gene, using NCBI build 36.1 annotation (National Center for Biotechnology Information, Bethesda MD). For 2 small genes, GABRD (chr. 1) and GABARAP (chr. 17), no markers within this region were available, so these genes were excluded from subsequent analyses. Because $\mathrm{GABA}_{\mathrm{A}}$ subunit genes in the chr. 15q cluster, GABRA5, GABRB3, and GABRG3 lie on an imprinted chromosomal region, in which only paternally transmitted copies of the genes are expressed (Meguro et al., 1997), markers on these genes would be inappropriate to assess using methods that do not account for the identity of the parent from whom each allele was transmitted, and were therefore excluded from analyses. All available SNPs on the Illumina 660w Quad array within the designated boundaries of each GABA-related gene that passed preliminary quality-control procedures were included in subsequent analyses. In all, 737 SNP markers in or near 31 genes (including 17 GABA receptor subunit genes) were retained (Table 2 ).

\section{Phenotypic Measures}

We examined 2 measures related to alcohol use and related psychopathology. First, we computed an index of drinking behaviors by taking the sum of 4 items drawn from a customized form of the Substance Abuse Module, an expansion to the World Health Organization's Composite International Diagnostic Interview (Robins et al., 1987). These were (i) frequency of alcohol use over the prior 12 months, (ii) average number of drinks consumed per alcohol use occasion over the prior 12 months, (iii) maximum number of alcoholic drinks ever consumed in a 24-hour period, and (iv) lifetime number of times ever having been intoxicated (the original text of all items is reproduced in the Supporting information). The 4 items were each scaled to an approximately common metric before being summed (scaling for each item is described in the Supporting information). Cronbach's alpha was 0.86 for the drinking index. Our second measure was a lifetime count of DSMIIIR alcohol abuse and dependence symptoms, ascertained in the course of a structured clinical diagnostic interview (MCTFR clinical assessments are described in more detail in Iacono et al., 1999). DSM-IIIR described the most current criteria at the time that assessments were conducted. Both the drinking behavior index and the alcohol abuse and dependence symptom count were log-transformed for analysis. Parents were not present when adolescents were questioned about their alcohol use and abuse behaviors.

\section{STATISTICAL ANALYSES}

\section{Single-SNP Analyses}

Analyses of individual SNPs were performed using a method incorporating a rapid feasible generalized least squares model (Li et al., 2011), which accounts for correlations among family members attributable to both genetic relatedness and shared environmental effects. SNPs were modeled under assumption of additive effect, entered as number of minor alleles $(0,1,2)$. For markers on chromosome $\mathrm{X}$, genotypes for male participants who possessed 1 minor allele were set to 2 minor alleles for analysis. To account for genetic ancestry, the first 10 principal components from an EIGENSTRAT analysis were included as covariates (Price et al., 2006). Other covariates included in single-SNP analyses were sex, age, birth year, generation (an indicator of whether an individual was a parent or child), a generation-by-age interaction, a generation-by-sex interac- 
Table 2. Chromosomal Location and Size of GABA System Genes

\begin{tabular}{|c|c|c|c|c|c|}
\hline Chromosome & Gene & SNPS & Gene $3^{\prime}$ end $-1 \mathrm{~kb}$ & Gene $5^{\prime}$ end $+5 \mathrm{~kb}$ & Total length (kb) \\
\hline 2 & $\mathrm{DBI}$ & 6 & 119839973 & 119851592 & 11.6 \\
\hline 2 & GAD1 & 7 & 171380445 & 171430905 & 50.5 \\
\hline 3 & SLC6A11 & 51 & 10831916 & 10960146 & 128.2 \\
\hline 3 & SLC6A1 & 31 & 11008420 & 11060935 & 52.5 \\
\hline 3 & GNAI2 & 3 & 50247650 & 50276790 & 29.1 \\
\hline 3 & GABRR3 & 16 & 99187216 & 99241521 & 54.3 \\
\hline 3 & GPR156 & 14 & 121366018 & 121450832 & 84.8 \\
\hline 4 & GABRG1 & 13 & 45731543 & 45825839 & 94.3 \\
\hline 4 & GABRA2 & 12 & 45945338 & 46091813 & 146.5 \\
\hline 4 & GABRA4 & 16 & 46614673 & 46696181 & 81.5 \\
\hline 4 & GABRB1 & 73 & 46727051 & 47128204 & 401.2 \\
\hline 5 & SLC6A7 & 15 & 149548712 & 149575828 & 27.1 \\
\hline 5 & GABRB2 & 45 & 160647013 & 160912708 & 265.7 \\
\hline 5 & GABRA6 & 6 & 161044235 & 161067176 & 22.9 \\
\hline 5 & GABRA1 & 8 & 161205774 & 161264543 & 58.8 \\
\hline 5 & GABRG2 & 19 & 161426225 & 161520123 & 93.9 \\
\hline 5 & GABRP & 12 & 170142300 & 170178628 & 36.3 \\
\hline 6 & GABBR1 & 10 & 29676983 & 29713941 & 37.0 \\
\hline 6 & GABRR1 & 31 & 89942941 & 89989215 & 46.3 \\
\hline 6 & GABRR2 & 27 & 90022957 & 90086686 & 63.7 \\
\hline 9 & GABBR2 & 147 & 100089184 & 100516300 & 427.1 \\
\hline 10 & GAD2 & 13 & 26544241 & 26638497 & 94.3 \\
\hline 12 & SLC6A12 & 8 & 168504 & 197874 & 29.4 \\
\hline 12 & SLC6A13 & 28 & 199049 & 247300 & 48.3 \\
\hline 12 & GABARAPL1 & 7 & 10255756 & 10271991 & 16.2 \\
\hline 16 & GABARAPL2 & 2 & 74156750 & 74174280 & 17.5 \\
\hline 19 & CACNA1A & 82 & 13177256 & 13483274 & 306.0 \\
\hline 20 & SLC32A1 & 2 & 36785518 & 36796429 & 10.9 \\
\hline 23 & GABRE & 11 & 150871251 & 150898807 & 27.6 \\
\hline 23 & GABRA3 & 20 & 151085289 & 151375487 & 290.2 \\
\hline 23 & GABRQ & 2 & 151556292 & 151577481 & 21.2 \\
\hline
\end{tabular}

GABA, $\gamma$-aminobutyric acid; SNP, single nucleotide polymorphism.

Gene end point positions based on NCBI RefSeq release 36.1.

tion, and a generation-by-birth-year interaction. We calculated the effective number of independent tests, accounting for LD patterns between the included markers in our sample, using the SimpleM method (Gao et al., 2008), which yielded an LD-inferred total of 485 effective independent tests and therefore a Bonferroni-corrected significance threshold of $0.05 / 485=0.0001$.

\section{GABA System Polygenic Scoring}

Genetic liability to alcohol dependence is likely to be substantially attributable to many variants, each contributing in only a small amount to the overall genetic risk. When many markers are examined separately for association with a complex trait, genuine genetic effects reflected by individual markers may be too small to overcome significance thresholds that account for multiple testing. However, the aggregated effects of multiple individually insignificant SNP markers combined into a single polygenic score may be associated with phenotypic variation (International Schizophrenia Consortium et al., 2009). For example, a similar approach has been used to calculate a score from multiple SNPs in dopamine system genes, which accounted for a small but significant percentage of variance in cocaine dependence symptomatology (Derringer et al., 2012).
When calculating a polygenic score from markers in GABA system genes, each SNP was permitted to contribute to the score only if its individual effect was such that the $p$-value associated with the marker was below a particular cutoff. Scores were calculated at 10 incrementally increasing $p$-value cutoffs ranging from $p<0.1$ to $p \leq 1.0$ (i.e., at the final threshold, all SNPs were permitted to contribute to the polygenic score). At each $p$-value cutoff threshold, allowing more markers of smaller individual effect to contribute to the score potentially resulted in an increase in the number of markers reflecting minute but genuine genotypic influences, but also permitted the inclusion of more markers that had $p$-values below the cutoff merely due to chance.

We calculated polygenic scores for each individual by summing the product of the genotypes (the number of minor alleles) and the regression coefficients from single-SNP analyses for all SNPs that were to be included in the score. However, because markers within the same gene, or in proximal genes, may be in LD with each other, to ensure that markers contributing to the polygenic score reflected unique association signals, it was necessary to prune the results of singleSNP analyses based on LD structure before calculating the GABA system polygenic score. We identified SNP pairs that were in substantial LD with each other, $r^{2}>0.5$, when only 
the founders of each family were considered $(1,852$ males, 2,130 females; 3,866 founders were parents, 116 founders were nonparent participants from families in which parental genotype data were not available). At each $p$-value threshold, for every pair of SNPs with LD $r^{2}>0.5$, in which both SNPs in the pair were below the current $p$-value threshold, the effect of the SNP with the higher $p$-value was set to 0 , so that the SNP did not contribute to the polygenic score. As a result, all SNPs that remained in the polygenic score after pruning were in low mutual LD $\left(r^{2}<0.5\right)$.

We used 10-fold cross-validation to account for overfitting. That is, for each of 10 iterations, polygenic scores were first derived from LD-pruned estimates of single-SNP effects in a training subsample comprising $90 \%$ of the overall sample. Training sample estimates were then used to predict the phenotypes of individuals in a separate testing subsample comprising the remaining $10 \%$ of the overall sample. Then, at each $p$-value threshold, polygenic score-based predictions were compared with the actual observed phenotypic values of individuals in the testing subsample using the coefficient of determination, averaged across all 10 iterations of the cross-validation procedure.

\section{SNP-Based Genetic Relationship Variance Estimates}

We also employed an estimate of phenotypic variance in alcohol-related phenotypes attributable to a given set of SNPs (GCTA; Yang et al., 2011). For both the set of GABA system SNPs (737 markers) and the entire set of available genome-wide SNP markers (527,829 markers), separately, an SNP-based measure of genetic relatedness between each pair of individuals included in the analysis was computed. For each analysis, the matrix of the genetic relatedness estimates for all pairs of individuals was then included as random effects in a linear mixed model (along with the covariates as fixed effects), using restricted maximum likelihood estimation, to estimate the proportion of phenotypic variance attributable to the SNPs used to compute interindividual genetic relatedness. To derive an estimate of variance attributable solely to the SNPs included in the analysis, unburdened by the shared environment or other sources of phenotypic variance, and unbiased by cryptic relatedness between individuals, one member of each pair with full-genome SNP-based genetic relatedness estimated at $>0.025$ was removed from subsequent analyses. For both the set of GABA system SNPs and the full-genome-wide set of SNPs, analyses were conducted separately for autosomal markers and markers on the $\mathrm{X}$ chromosome. This approach, based on a calculation of genetic relatedness from the simultaneous consideration of all of the SNPs in a particular set, does not provide information regarding the effects of individual SNP effects, but also does not suffer from the inaccuracy of prediction that affects polygenic scores due to error on the estimates of the effects of the individual SNPs that contribute to the score (Visscher et al., 2010).

\section{Gene-Based Testing}

Finally, we assessed the effect of individual GABA system genes using a gene-based test (VEGAS; Liu et al., 2010), which combines the test statistics from single-SNP analyses of all markers within a particular gene and then compares the resulting gene-based test statistic to a large number of simulated chi-square distributed gene-based test statistics, which are produced taking into account HapMap (CEU) LD structure and gene length, and which approximate the observed gene-based test statistic under the null hypothesis. The $p$-value resulting from this gene-based test is thus the proportion of simulated test statistics that exceed the observed test statistic. This form of analysis can reveal whether there are disproportionately many markers with low $p$-values in a given gene. We also performed a variation on the gene-based test (the "Top-SNP" method), which compares the top-ranked marker in each gene to the simulated maximum element (itself the test statistic of a chi-squared 1 df variable) of the gene-based test statistic.

\section{RESULTS}

The $p$-value-ranked top 10 results from the analyses of the 737 single-SNP marker associations with both alcohol use phenotypes are displayed in Table 3. No single marker for either phenotype reached the LD-adjusted significance threshold of 0.0001 , which corrects for the multiple testing. For both phenotypes, Manhattan plots and QQ plots for the results of single-SNP association analyses are shown on Figs S1-S4.

Ignoring relatedness and assuming complete independence between participants, among the full sample of ever-drinking participants, there was $>80 \%$ power to detect additive perallele individual SNP effects as small as a 0.09 difference in alcohol abuse and dependence symptom count, or a 0.13 difference in the drinking index, corresponding to a difference in $R^{2}=0.004$ for either phenotype. Assuming full dependence between first-degree relatives, and therefore basing calculations only on founders who had ever had a drink, there was $>80 \%$ power to detect individual SNP effects of 0.11 alcohol abuse and dependence symptoms per allele and a 0.16 difference in the drinking index per allele, corresponding to a difference in $R^{2}=0.006$. The mean cross-validated squared correlations between polygenic score-predicted phenotypic values and observed phenotypic values at each of 10 $p$-value thresholds are shown in Table 4 . The mean was computed as a weighted average of the 10 squared correlations with weight given as the sign of the unsquared correlation. A few of the resulting means were slightly negative but truncated to 0 because a squared correlation cannot be negative. The cross-validated squared correlation was uniformly small (in no case even approaching 1\%) and not significant at any threshold for either phenotype. Ignoring relatedness and assuming independence between participants, we had $68 \%$ power to detect the largest observed $R^{2}$ of approximately 
Table 3. Top 10 Associations of Individual SNPs with Alcohol Use and Abuse Phenotypes

\begin{tabular}{|c|c|c|c|c|c|}
\hline SNP ID & Gene & Chromosome & Location (bp) & Coefficient & $p$-Value \\
\hline \multicolumn{6}{|l|}{ Drinking index } \\
\hline rs1502017 & CACNA1A & 19 & 13291324 & -0.030 & 0.006 \\
\hline rs3798256 & GABRR2 & 6 & 90053124 & 0.021 & 0.006 \\
\hline rs16027 & CACNA1A & 19 & 13258560 & 0.033 & 0.010 \\
\hline rs12608501 & CACNA1A & 19 & 13263072 & 0.033 & 0.011 \\
\hline rs497740 & SLC6A13 & 12 & 205216 & 0.019 & 0.014 \\
\hline rs6478792 & GABBR2 & 9 & 100441292 & 0.034 & 0.015 \\
\hline rs2292037 & CACNA1A & 19 & 13288805 & -0.022 & 0.015 \\
\hline rs453561 & GABRR1 & 6 & 89961591 & -0.018 & 0.019 \\
\hline rs7250783 & CACNA1A & 19 & 13237536 & -0.020 & 0.020 \\
\hline rs6454748 & GABRR2 & 6 & 90051670 & -0.017 & 0.021 \\
\hline \multicolumn{6}{|c|}{ Alcohol abuse and dependence symptoms } \\
\hline rs1994260 & SLC6A11 & 3 & 10913584 & 0.040 & 0.002 \\
\hline rs12196758 & GABRR2 & 6 & 90052018 & 0.053 & 0.004 \\
\hline rs16916777 & GABBR2 & 9 & 100320996 & 0.110 & 0.005 \\
\hline rs2900964 & CACNA1A & 19 & 13413763 & 0.056 & 0.005 \\
\hline rs2046423 & SLC6A11 & 3 & 10899076 & 0.034 & 0.008 \\
\hline rs12206367 & GABRR2 & 6 & 90031345 & 0.043 & 0.010 \\
\hline rs6826708 & GABRB1 & 4 & 47047872 & -0.051 & 0.011 \\
\hline rs9451192 & GABRR2 & 6 & 90033091 & -0.029 & 0.011 \\
\hline rs2655278 & SLC6A11 & 3 & 10908887 & 0.032 & 0.011 \\
\hline rs4524525 & GABRP & 5 & 170141772 & -0.031 & 0.011 \\
\hline
\end{tabular}

SNP, single nucleotide polymorphism.

Table 4. Mean Cross-Validated (CV) Correlations Between Polygenic Score-Predicted Alcohol Use and Abuse Phenotypic Values and Observed Phenotypic Values at Each of $10 p$-value Thresholds

\begin{tabular}{lcc}
\hline $\begin{array}{c}p \text {-Value } \\
\text { threshold }\end{array}$ & $\begin{array}{c}\text { Drinking index } \\
\text { mean CV } R^{2}\end{array}$ & $\begin{array}{r}\text { Alcohol abuse and dependence } \\
\text { symptoms mean CV } R^{2}\end{array}$ \\
\hline$<0.1$ & 0 & 0.00096 \\
$<0.2$ & 0 & 0.00052 \\
$<0.3$ & 0 & 0.00015 \\
$<0.4$ & 0 & 0.00054 \\
$<0.5$ & 0 & 0 \\
$<0.6$ & 0 & 0 \\
$<0.7$ & 0 & 0 \\
$<0.8$ & 0 & 0.00021 \\
$<0.9$ & 0 & 0 \\
All SNPs included & 0 & 0 \\
\hline
\end{tabular}

SNP, single nucleotide polymorphism.

0.001 (for alcohol abuse and dependence symptoms at the $p<0.1$ level, nonsignificant). Among ever-drinking founders only, we had $49 \%$ power to detect an $R^{2}=0.001$, for either phenotype. To obtain $>80 \%$ power to detect a polygenic effect of $R^{2}=0.001$ or smaller would require a sample size of at least $N=8,173$ independent (nonrelated) participants.

Estimates of explained phenotypic variance $\left(h_{\mathrm{SNP}}^{2}\right)$ attributable to GABA system SNPs and all available SNPs, separately for autosomal and chromosome $\mathrm{X}$ markers, are shown in Table 5. Only the variance in the drinking index attributable to the full set of all available autosomal SNPs was significant, using a likelihood ratio test of the null hypothesis that for each group of SNPs, $h_{\mathrm{SNP}}^{2}=0$. Neither autosomal nor chromosome X GABA system SNPs accounted for a significant proportion of the variance in either alcohol-related phenotype.
Table 5. Estimates of Explained Phenotypic Variance $\left(h_{\mathrm{SNP}}^{2}\right)$ Attributable to GABA System SNPs and all Available SNPs, Separately for Autosomal and Chromosome X Markers

\begin{tabular}{lcr}
\hline & $\begin{array}{c}\text { Drinking index } \\
h_{\text {SNP }}^{2}(\text { SE) }\end{array}$ & $\begin{array}{c}\text { Alcohol abuse } \\
\text { and dependence symptoms } \\
h_{\text {SNP }}^{2}(\text { SE) }\end{array}$ \\
\hline All autosomal SNPs & $0.156^{*}(0.100)$ & $0.09(0.100)$ \\
GABA autosomal SNPs & $0(0.006)$ & $0(0.006)$ \\
All chr. X SNPs & $0(0.016)$ & $0.001(0.016)$ \\
GABA chr. X SNPs & $0(0.001)$ & $0(0.001)$ \\
\hline
\end{tabular}

GABA, $\gamma$-aminobutyric acid; SNPs, single nucleotide polymorphisms.

Analyzed $N=3,614$ for the drinking index and analyzed $N=3,621$ for alcohol abuse and dependence symptoms.

*Likelihood ratio test $p<0.05$.

The $p$-value-ranked top 10 results of gene-based tests for both phenotypes are displayed in Table 6 , and the top 10 results from the "Top-SNP" variation on the gene-based test are shown in Table 7. For neither phenotype did any gene or top-ranked SNP per gene meet the Bonferroni-corrected significance threshold of 0.0016 for 31 independent tests.

Because parents were older than nonparent participants, were more likely to have ever had a drink, had higher levels on most measures of quantity and frequency of alcohol use, and had higher rates of endorsement of alcohol dependence and abuse symptoms, in addition to the analyses conducted on the full sample of ever-drinking participants as described above, we also conducted all analyses separately for everdrinking parents and nonparents. The results of these analyses are described in Tables S1A through S5B. Separate parent and nonparent results are consistent with results from the full sample, in that for neither subgroup did polymor- 
Table 6. Top 10 Associations with Alcohol Use and Abuse Phenotypes from Gene-Based Tests

\begin{tabular}{lrl}
\hline Gene & Chromosome & $p$-Value \\
\hline Drinking index & & \\
GABRR2 & 6 & 0.100 \\
GABRA6 & 5 & 0.124 \\
GABRR1 & 6 & 0.156 \\
SLC6A12 & 12 & 0.168 \\
SLC6A13 & 12 & 0.187 \\
CACNA1A & 19 & 0.195 \\
GNAI2 & 3 & 0.208 \\
SLC6A7 & 5 & 0.231 \\
GABARAPL1 & 12 & 0.234 \\
GAD1 & 2 & 0.245 \\
Alcohol abuse and dependence symptoms & \\
GABRR2 & 6 & 0.038 \\
GABRP & 5 & 0.042 \\
SLC6A11 & 3 & 0.079 \\
GABRR3 & 3 & 0.149 \\
GABRA6 & 5 & 0.182 \\
SLC6A12 & 12 & 0.195 \\
GABRR1 & 6 & 0.202 \\
SLC6A13 & 12 & 0.202 \\
GABRB1 & 4 & 0.240 \\
SLC6A1 & 3 & 0.250 \\
\hline
\end{tabular}

Table 7. Top 10 Associations with Alcohol Use and Abuse Phenotypes from "Top-SNP" Gene-Based Tests

\begin{tabular}{lcll}
\hline Gene & Chromosome & Top-SNP & $p$-Value \\
\hline Drinking index & & & \\
GABRR2 & 6 & rs3798256 & 0.149 \\
GAD1 & 2 & rs16858988 & 0.153 \\
GNAl2 & 3 & rs11716295 & 0.165 \\
GABARAPL1 & 12 & rs11053685 & 0.2 \\
GABRA6 & 5 & rs12515485 & 0.206 \\
GPR156 & 3 & rs7648922 & 0.239 \\
SLC6A13 & 12 & rs497740 & 0.271 \\
SLC6A12 & 12 & rs497740 & 0.278 \\
CACNA1A & 19 & rs1502017 & 0.292 \\
GABRR1 & 6 & rs453561 & 0.332 \\
Alcohol abuse and dependence symptoms & & \\
SLC6A11 & 3 & rs1994260 & 0.065 \\
GABRP & 5 & rs4524525 & 0.073 \\
GABRR2 & 6 & rs12196758 & 0.105 \\
GABRA4 & 4 & rs7658410 & 0.189 \\
GABRR1 & 6 & rs12206367 & 0.209 \\
SLC6A1 & 3 & rs9990174 & 0.244 \\
CACNA1A & 19 & rs2900964 & 0.265 \\
GABRA6 & 5 & rs12515485 & 0.266 \\
SLC6A12 & 12 & rs17800720 & 0.296 \\
GABRR3 & 3 & rs12695642 & 0.298 \\
\hline
\end{tabular}

SNP, single nucleotide polymorphism.

phisms in GABA systems have any significant effect using any analytical method.

\section{DISCUSSION}

$\mathrm{GABA}_{\mathrm{A}}$ receptors are involved in mediating both the acute and chronic effects of alcohol (Kumar et al., 2009), and markers in GABA system genes have been associated in a number of studies with alcohol dependence and other alcohol-related phenotypes (Cui et al., 2012). We used multiple methods to interrogate the potential relationship between alcohol use and abuse phenotypes and variation in GABA system markers, either taken individually or aggregated using different methods, but no association was evident in any of them.

In analyses of individual SNPs, none approached the thresholds for significance determined by an appropriately stringent correction for multiple testing for either the drinking index or the count of alcohol abuse and dependence symptoms.

A polygenic score, which selectively retained and aggregated the GABA system markers of highest potential effect, was likewise unable to account for variation in either alcohol use phenotype. As any true effects associated with the markers contributing to the polygenic score would be very small, it is possible that error on each of the individual estimates of single-SNP effects resulted in the score failing to account for phenotypic variance (Visscher et al., 2010).

Similarly, estimates based on pairwise relationships between individuals, derived from all of the GABA system markers in the autosome and on the $\mathrm{X}$ chromosome, did not explain any of the variance in alcohol use or symptomatology. The proportion of variance in the 2 alcohol use variables explained by all available autosomal SNPs (but not all available chromosome X SNPs) is appreciable, approximating or exceeding $10 \%$, although less than most similar pedigreebased estimates (Grant et al., 2009; Slutske et al., 1999) and statistically significant only for the drinking index. This is likely because pairwise genetic correlations computed using this method only reflect the common variants that are tagged by the available genotyped SNPs (Yang et al., 2011).

In line with results from other analysis methods, genebased tests did not indicate that SNPs with low $p$-values were significantly overrepresented in any GABA system gene, nor that the "Top-SNP" in any gene was likely to represent a genuine genetic effect.

Many previous studies indicating a role for GABA system genetic variation in alcohol dependence were conducted using as cases individuals drawn from treatment programs for alcohol dependence or other clinical settings (e.g., Lappalainen et al., 2005). Some, such as those involving the samples from the Collaborative Studies on Genetics of Alcoholism (Rice et al., 2003), included participants belonging to families of probands with multiple alcohol-dependent first-degree relatives (Agrawal et al., 2006; Edenberg et al., 2004). Alcohol-dependent cases with severe phenotypes and family history of alcohol dependence may have an elevated genetic loading for the disorder, making the detection of genetic effects more likely. In one clinically derived sample, associations between markers in GABRA2 and alcohol dependence increased when analyses were restricted to include as cases only individuals with indicators of severe or persistent alcohol dependence, or a family history of alcohol dependence (Fehr et al., 2006). Other studies suggest that GABRA2-related alcohol dependence vulnerability is limited 
to individuals with comorbid dependence on illicit drugs (Agrawal et al., 2006) or that GABRA2 markers are related to polysubstance abuse, but not alcohol dependence alone (Drgon et al., 2006). In contrast, the MTFS and SIBS samples used in the present study are community-based, reflecting psychopathology at rates and levels representative of the general population. As such, measures of the quantity and frequency of alcohol use, as well as the endorsement of alcohol-related symptomatology, are low relative to clinically derived samples or samples selected for a family history of alcohol-related psychopathology. Further, many participants were still in adolescence at the time of assessment (minimum age 16.5) and were therefore less likely to have ever tried alcohol and less likely to exhibit heavy alcohol use or alcohol-related symptomatology than adult participants. However, there have been instances of GABRA2 SNPs being associated with alcohol dependence in samples drawn from the general population (e.g., Covault et al., 2004).

The GABA system gene by far most frequently implicated in alcohol-related behaviors and other substance-related and externalizing behaviors is the $\mathrm{GABA}_{\mathrm{A}}$ receptor $\alpha 2$ subunit gene GABRA2. The SNP rs279858, although lying in exon 5 of the gene, is a synonymous substitution (Covault et al., 2004). It has been associated, either individually or as a member of multi-SNP haplotypes, with alcohol dependence and other alcohol-related phenotypes, such as alcohol sensitivity, more often than any other marker in GABRA2 (Cui et al., 2012). Although the genome-wide array upon which markers were genotyped for our study did not include rs279858, it did include markers in the same region of the gene (rs1808851, rs279856), which were in perfect LD with rs279858 in a HapMap reference panel of European descent (CEU) (Johnson et al., 2008) - but neither of which were associated at even a nominal level with either the drinking index or alcohol abuse and dependence symptom count. Synonymous SNPs can affect protein functioning and expression via a number of different mechanisms (Hunt et al., 2009), so genotyping the exact SNP associated with alcohol-related phenotypes in previous studies may be critical.

In previous studies, GABA system markers have been associated with a variety of phenotypes in a number of different contexts, many of which were not assessed in this study. For example, there is evidence that the influence of polymorphisms in the GABA system may vary with age or across developmental stages (Dick et al., 2006, 2009) and be moderated by environmental factors (Dick et al., 2009; Enoch et al., 2010). Interaction may also occur within and between GABA system genes, particularly among proximal or clustered genes (Uusi-Oukari et al., 2000). Markers in GABA system genes have also been associated with less complex biological markers such as beta-frequency EEG (Edenberg et al., 2004) and event-related potentials (Winterer et al., 2000) that meet the criteria to be considered endophenotypes more directly reflecting underlying genetic liability than their complex behavioral correlates (Begleiter and Porjesz, 2006).
To conclude, using data from a large, community-based sample, we sought to determine whether polymorphisms in GABA system genes, including both $\mathrm{GABA}_{\mathrm{A}}$ receptor subunit genes and other genes involved in GABAergic structure or function, were related to variation in an index of quantity and frequency of alcohol use, or a measure of alcohol abuse and dependence symptomatology. Using multiple methods, we assessed the effect of GABA system gene markers individually, in aggregate, as they determined the magnitude of an estimate of variance derived from SNP-based pairwise genetic relationships between participants and in a genebased test. In no case were GABA system SNPs consistently related to alcohol use nor the symptomatology of alcoholrelated psychopathology. Given this study's limitations, continued research is necessary to determine the circumstances in which GABA system variants might influence alcoholrelated phenotype.

\section{ACKNOWLEDGMENTS}

Supported in part by NIH grants DA05147, AA09367, AA11886, DA13240, MH66140, and DA024417.

\section{REFERENCES}

Addolorato G, Caputo F, Capristo E, Domenicali M, Bernardi M, Janiri L, Agabio R, Colombo G, Gessa GL, Gasbarrini G (2002) Baclofen efficacy in reducing alcohol craving and intake: a preliminary double-blind randomized controlled study. Alcohol Alcohol 37:504-508.

Agrawal A, Edenberg HJ, Foroud T, Bierut LJ, Dunne G, Hinrichs AL, Nurnberger JI, Crowe R, Kuperman S, Schuckit MA, Begleiter H, Porjesz B, Dick DM (2006) Association of GABRA2 with drug dependence in the collaborative study of the genetics of alcoholism sample. Behav Genet 36:640-650.

Begleiter H, Porjesz B (2006) Genetics of human brain oscillations. Int J Psychophysiol 60:162-171.

Bettler B, Kaupmann K, Mosbacher J, Gassmann M (2004) Molecular structure and physiological functions of GABA(B) receptors. Physiol Rev 84:835-867.

Boyle AE, Segal R, Smith BR, Amit Z (1993) Bidirectional effects of gabaergic agonists and antagonists on maintenance of voluntary ethanol intake in rats. Pharmacol Biochem Behav 46:179-182.

Covault J, Gelernter J, Hesselbrock V, Nellissery M, Kranzler HR (2004) Allelic and haplotypic association of GABRA2 with alcohol dependence. Am J Med Genet B Neuropsychiatr Genet 129B:104-109.

Cui WY, Seneviratne C, Gu J, Li MD (2012) Genetics of GABAergic signaling in nicotine and alcohol dependence. Hum Genet 131:843-855.

Derringer J, Krueger RF, Dick DM, Aliev F, Grucza RA, Saccone S, Agrawal A, Edenberg HJ, Goate AM, Hesselbrock VM, Kramer JR, Lin P, Neuman RJ, Nurnberger JI Jr, Rice JP, Tischfield JA, Bierut LJ (2012) The aggregate effect of dopamine genes on dependence symptoms among cocaine users: cross-validation of a candidate system scoring approach. Behav Genet 42:626-635.

Dick DM, Bierut L, Hinrichs A, Fox L, Bucholz KK, Kramer J, Kuperman S, Hesselbrock V, Schuckit M (2006) The role of GABRA2 in risk for conduct disorder and alcohol and drug dependence across developmental stages. Behav Genet 36:577-590.

Dick DM, Latendresse SJ, Lansford JE, Budde JP, Goate A, Dodge KA, Pettit GS, Bates JE (2009) Role of GABRA2 in trajectories of externalizing behavior across development and evidence of moderation by parental monitoring. Arch Gen Psychiatry 66:649-657. 
Drgon T, D'Addario C, Uhl GR (2006) Linkage disequilibrium, haplotype and association studies of a chromosome 4 GABA receptor gene cluster: candidate gene variants for addictions. Am J Med Genet B Neuropsychiatr Genet 141B:854-860.

Edenberg HJ, Dick DM, Xuei X, Tian H, Almasy L, Bauer LO, Crowe RR, Goate A, Hesselbrock V, Jones K, Kwon J, Li T, Nurnberger JI Jr, O'Connor SJ, Reich T, Rice J, Schuckit MA, Porjesz B, Foroud T, Begleiter $\mathrm{H}$ (2004) Variations in GABRA2, encoding the $\alpha 2$ subunit of the $\mathrm{GABA}_{\mathrm{A}}$ receptor, are associated with alcohol dependence and with brain oscillations. Am J Hum Genet 74:705-714.

Enoch M (2008) The role of $\mathrm{GABA}_{\mathrm{A}}$ receptors in the development of alcoholism. Pharmacol Biochem Behav 90:95-104.

Enoch MA, Hodgkinson CA, Yuan Q, Shen PH, Goldman D, Roy A (2010) The influence of GABRA2, childhood trauma, and their interaction on alcohol, heroin, and cocaine dependence. Biol Psychiatry 67:20-27.

Enoch MA, Zhou Z, Kimura M, Mash DC, Yuan Q, Goldman D (2012) GABAergic gene expression in postmortem hippocampus from alcoholics and cocaine addicts; corresponding findings in alcohol-naive $\mathrm{P}$ and NP rats. PLoS ONE 7:e29369.

Fehr C, Sander T, Tadic A, Lenzen KP, Anghelescu I, Klawe C, Dahmen N, Schmidt LG, Szegedi A (2006) Confirmation of association of the GABRA2 gene with alcohol dependence by subtype-specific analysis. Psychiatr Genet 16:9-17.

Gao X, Starmer J, Martin ER (2008) A multiple testing correction method for genetic association studies using correlated single nucleotide polymorphisms. Genet Epidemiol 32:361-369.

Grant JD, Agrawal A, Bucholz KK, Madden PA, Pergadia ML, Nelson EC, Lynskey MT, Todd RD, Todorov AA, Hansell NK, Whitfield JB, Martin NG, Heath AC (2009) Alcohol consumption indices of genetic risk for alcohol dependence. Biol Psychiatry 66:795-800.

Grobin AC, Matthews DB, Devaud LL, Morrow AL (1998) The role of $\mathrm{GABA}_{\mathrm{A}}$ receptors in the acute and chronic effects of ethanol. Psychopharmacology 139:2-19.

Heath AC, Martin NG (1994) Genetic influences on alcohol consumption patterns and problem drinking: results from the Australian NH\&MRC twin panel follow-up survey. Ann N Y Acad Sci 708:72-85.

Hodgkinson CA, Yuan Q, Xu K, Shen PH, Heinz E, Lobos EA, Binder EB, Cubells J, Ehlers CL, Gelernter J, Mann J, Riley B, Roy A, Tabakoff B, Todd RD, Zhou Z, Goldman D (2008) Addictions biology: haplotypebased analysis for 130 candidate genes on a single array. Alcohol Alcohol 43:505-515.

Hunt R, Sauna ZE, Ambudkar SV, Gottesman MM, Kimchi-Sarfaty C (2009) Silent (synonymous) SNPs: should we care about them? Methods Mol Biol 578:23-39.

Iacono WG, Carlson SR, Taylor J, Elkins IJ, McGue M (1999) Behavioral disinhibition and the development of substance-use disorders: findings from the Minnesota Twin Family Study. Dev Psychopathol 11:869-900.

Iacono WG, McGue M, Krueger RF (2006) Minnesota Center for Twin and Family Research. Twin Res Hum Genet 9:978-984.

International Schizophrenia Consortium, Purcell SM, Wray NR, Stone JL, Visscher PM, O'Donovan MC, Sullivan PF, Sklar P (2009) Common polygenic variation contributes to risk of schizophrenia and bipolar disorder. Nature 460:748-752.

Johnson AD, Handsaker RE, Pulit SL, Nizzari MM, O'Donnell CJ, de Bakker PI (2008) SNAP: a web-based tool for identification and annotation of proxy SNPs using HapMap. Bioinformatics 24:2938-2939.

Kanehisa M (1996) Toward pathway engineering: a new database of genetic and molecular pathways. Sci Technol Japan 59:34-38.

Koob GF (2006) A role for GABA in alcohol dependence. Adv Pharmacol 54:205-229.

Kumar S, Porcu P, Werner DF, Matthews DB, Diaz-Granados JL, Helfand RS, Morrow AL (2009) The role of $\mathrm{GABA}_{\mathrm{A}}$ receptors in the acute and chronic effects of ethanol: a decade of progress. Psychopharmacology 205:529-564.

Kuo PH, Kalsi G, Prescott CA, Hodgkinson CA, Goldman D, Alexander J, van den Oord EJ, Chen X, Sullivan PF, Patterson DG, Walsh D, Kendler
KS, Riley BP (2009) Associations of glutamate decarboxylase genes with initial sensitivity and age-at-onset of alcohol dependence in the Irish Affected Sib Pair Study of Alcohol Dependence. Drug Alcohol Depend 101:80-87.

Lappalainen J, Krupitsky E, Remizov M, Pchelina S, Taraskina A, Zvartau E, Somberg LK, Covault J, Kranzler HR (2005) Association between alcoholism and $\gamma$-amino butyric acid a2 receptor subtype in a Russian population. Alcohol Clin Exp Res 29:493-498.

Li X, Basu S, Miller MB, Iacono WG, McGue M (2011) A rapid generalized least squares model for a genome-wide quantitative trait association analysis in families. Hum Hered 71:67-82.

Lind PA, Macgregor S, Agrawal A, Montgomery GW, Heath AC, Martin NG, Whitfield JB (2008a) The role of GABRA2 in alcohol dependence, smoking, and illicit drug use in an Australian population sample. Alcohol Clin Exp Res 32:1721-1731.

Lind PA, MacGregor S, Montgomery GW, Heath AC, Martin NG, Whitfield JB (2008b) Effects of GABRA2 variation on physiological, psychomotor and subjective responses in the alcohol challenge twin study. Twin Res Hum Genet 11:174-182.

Liu JZ, McRae AF, Nyholt DR, Medland SE, Wray NR, Brown KM, Hayward NK, Montgomery GW, Visscher PM, Martin NG, Macgregor S (2010) A versatile gene-based test for genome-wide association studies. Am J Hum Genet 87:139-145.

Lobo IA, Harris RA (2008) GABA(A) receptors and alcohol. Pharmacol Biochem Behav 90:90-94.

Matthews AG, Hoffman EK, Zezza N, Stiffler S, Hill SY (2007) The role of the GABRA2 polymorphism in multiplex alcohol dependence families with minimal comorbidity: within-family association and linkage analyses. J Stud Alcohol Drugs 68:625-633.

McGue M (1999) The behavioral genetics of alcoholism. Curr Dir Psychol Sci 8:109-115.

McGue M, Keyes M, Sharma A, Elkins I, Legrand L, Johnson W, Iacono WG (2007) The environments of adopted and non-adopted youth: evidence on range restriction from the Sibling Interaction and Behavior Study (SIBS). Behav Genet 37:449-462.

Meguro M, Mitsuya K, Sui H, Shigenami K, Kugoh H, Nakao M, Oshimura M (1997) Evidence for uniparental, paternal expression of the human GABAA receptor subunit genes, using microcell-mediated chromosome transfer. Hum Mol Genet 6:2127-2133.

Miller MB, Basu S, Cunningham J, Eskin E, Malone SM, Oetting W, Schork N, Sul J, Iacono WG, McGue M (2012) The Minnesota Center for Twin and Family Research genome-wide association study. Twin Res Hum Genet 15:767-774.

Onori N, Turchi C, Solito G, Gesuita R, Buscemi L, Tagliabracci A (2010) GABRA2 and alcohol use disorders: no evidence of an association in an Italian case-control study. Alcohol Clin Exp Res 34:659-668.

Price AL, Patterson NJ, Plenge RM, Weinblatt ME, Shadick NA, Reich D (2006) Principal components analysis corrects for stratification in genomewide association studies. Nat Genet 38:904-909.

Rice JP, Saccone NL, Foroud T, Edenberg HJ, Nurnberger Jr. J, Goate A, Crowe RR, Hesselbrock V, Schuckit M, Porjesz B, Reich T, Begleiter H (2003) Alcoholism: Collaborative Study on the Genetics of Alcoholism (COGA), in Nature Encyclopedia of the Human Genome. (Kauffman G ed), pp 60-65. Macmillan Publishers Ltd., Nature Publishing Group, Hampshire.

Robins LN, Babor T, Cottler LB (1987) Composite International Diagnostic Interview: Expanded Substance Abuse Module. Washington University, Department of Psychiatry, St. Louis, MO.

Saccone SF, Bierut LJ, Chesler EJ, Kalivas PW, Lerman C, Saccone NL, Uhl GR, Li CY, Philip VM, Edenberg HJ, Sherry ST, Feolo M, Moyzis RK, Rutter JL (2009) Supplementing high-density SNP microarrays for additional coverage of disease-related genes: addiction as a paradigm. PLoS ONE 4:e5225.

Sander T, Samochowiec J, Ladehoff M, Smolka M, Peters C, Riess O, Rommelspacher H, Schmidt LG (1999) Association analysis of exonic variants of the gene encoding the GABAB receptor and alcohol dependence. Psychiatr Genet 9:69-73. 
Slutske WS, True WR, Scherrer JF, Heath AC, Bucholz KK, Eisen SA, Goldberg J, Lyons MJ, Tsuang MT (1999) The heritability of alcoholism symptoms: "indicators of genetic and environmental influence in alcoholdependent individuals" revisited. Alcohol Clin Exp Res 23:759-769.

Uusi-Oukari M, Heikkila J, Sinkkonen ST, Makela R, Hauer B, Homanics GE, Sieghart W, Wisden W, Korpi ER (2000) Long-range interactions in neuronal gene expression: evidence from gene targeting in the $\mathrm{GABA}_{\mathrm{A}}$ receptor $\beta 2-\alpha 6-\alpha 1-\gamma 2$ subunit gene cluster. Mol Cell Neurosci 16:34 41 .

Visscher PM, Yang J, Goddard ME (2010) A commentary on 'common SNPs explain a large proportion of the heritability for human height' by Yang et al. (2010). Twin Res Hum Genet 13:517-524.

Winterer G, Smolka M, Samochowiec J, Mulert C, Ziller M, Mahlberg R, Wuebben Y, Gallinat J (2000) Association analysis of $\mathrm{GABA}_{\mathrm{A}} \beta_{2}$ and $\gamma_{2}$ gene polymorphisms with event-related prefrontal activity in man. Hum Genet 107:513-518.

Yang J, Lee SH, Goddard ME, Visscher PM (2011) GCTA: a tool for genome-wide complex trait analysis. Am J Hum Genet 88:76-82.

\section{SUPPORTING INFORMATION}

Additional Supporting Information may be found in the online version of this article:

Fig. S1. Manhattan plot for $p$-values from single-marker drinking index analysis.

Fig. S2. Manhattan plot for $p$-values from single-marker alcohol dependence and abuse symptom count analysis.

Fig. S3. Quantile-quantile plot for $p$-values from single-marker drinking index analysis.

Fig. S4. Quantile-quantile plot for $p$-values from single-marker alcohol dependence and abuse symptom count analysis.
Table S1. (A) Top 10 associations of individual SNPs with alcohol use and abuse phenotypes among parents. (B) Top 10 associations of individual SNPs with alcohol use and abuse phenotypes among nonparents.

Table S2. (A) Mean cross-validated correlations between polygenic score-predicted alcohol use and abuse phenotypic values and observed phenotypic values at each of $10 p$-value thresholds among parents. (B) Mean cross-validated correlations between polygenic score-predicted alcohol use and abuse phenotypic values and observed phenotypic values at each of $10 p$-value thresholds among nonparents.

Table S3. (A) Estimates of explained phenotypic variance $\left(h_{\mathrm{SNP}}^{2}\right)$ attributable to GABA system SNPs and all available SNPs, separately for autosomal and chromosome X markers among parents. (B) Estimates of explained phenotypic variance $\left(h_{\mathrm{SNP}}^{2}\right)$ attributable to GABA system SNPs and all available SNPs, separately for autosomal and chromosome X markers among nonparents.

Table S4. (A) Top 10 associations with alcohol use and abuse phenotypes from gene-based tests among parents. (B) Top 10 associations with alcohol use and abuse phenotypes from gene-based tests among nonparents.

Table S5. (A) Top 10 associations with alcohol use and abuse phenotypes from "Top-SNP" gene-based tests among parents. (B) Top 10 associations with alcohol use and abuse phenotypes from "Top-SNP" gene-based tests among nonparents.

Data S1. Drinking index. 